\title{
The dissociation of visuospatial neglect and neglect dyslexia
}

\author{
ANGELA DE LACY COSTELLO, ELIZABETH K WARRINGTON \\ From the National Hospital for Nervous Diseases, Queen Square, London, UK
}

SUMMARY A right-handed man with a left hemisphere lesion extending into the right hemisphere, with evidence of both a left-sided neglect dyslexia and right-sided visuospatial neglect is reported. When copying simple geometric designs he omitted to copy figures on the right-hand side of the page, when bisecting lines he tended to bisect the line to the left of the line's actual centre. He had a neglect dyslexia which was characterised by paralexic errors affecting the beginning (that is, left) of words. The occurrence of these two phenomena provides evidence of a dissociation of these forms of neglect. The findings are discussed in relation to the possible mechanisms of unilateral neglect.

Visual neglect syndrome is the tendency of patients with cerebral damage or disease to neglect or ignore visual stimuli that appear contralateral to the affected hemisphere. Thus counting or pointing to scattered objects may be limited to those lying on the right while those on the left are completely ignored or found after a long delay. In copying drawings the patient may omit the lines on the left, even when the drawing has a well known symmetric configuration which should suggest its completion. In prose reading the patient with left-sided neglect may omit the words at the beginning of a line.

More recently a neglect phenomenon affecting single word reading has been described. Patients have been observed to make paralexic errors affecting predominantly the right of the word ${ }^{1}$ or more commonly the left of the word. ${ }^{2-4}$ These syndromes have been termed neglect dyslexia.

The physiological basis of neglect has been the subject of considerable debate. There would appear to be two major groups of theory to explain neglect phenomena. On the one hand there are the theories that have emphasised a failure of sensory processing implying an input locus for such effects, ${ }^{5-7}$ and on the other hand there are theories that appear to implicate a more central locus. Heilman and Valenstein ${ }^{8}$ and Watson and associates ${ }^{9}$ have postulated an attention-arousal hypothesis whereby neglect is con-

Address for reprint requests: Professor E K Warrington, the National Hospital for Nervous Diseases, Queen Square, London WCIN 3BG, UK.

Received 17 October 1986. Accepted 13 November 1986 sidered to be a unilateral deficit in the system which alerts the organism to enable it to deal with sensory events occurring in the contralateral half of space. Bisiach $^{10-12}$ has been most explicit in accounting for all aspects of unilateral neglect in terms of a faulty internal representation of visual events in extrapersonal space. This position was much strengthened by the observation of a neglect dysgraphic, a patient who in oral spelling made errors at the beginnings of words. ${ }^{4}$

Ellis $e t a l^{3}$ interpret both unilateral spatial neglect and neglect dyslexia as deriving from a common faulty processing in the input of visuospatial information. Indeed they go as far as to predict that neglect dyslexia will not occur in the absence of any other features of unilateral visual neglect. That is, the particular features of neglect are held to reflect a continuum of task difficulty. However, neither of these accounts of neglect allows the possibility that the various neglect phenomena fractionate and may have different underlying mechanisms. Yet there is already some evidence that this is the case.

In the original six cases of neglect dyslexia described by Kinsbourne and Warringto ${ }^{2}$ there was only a very loose correlation between neglect in reading and neglect in other visual tasks. There was no evidence of more general neglect in the neglect dyslexia, JAF, reported by Baxter and Warrington ${ }^{4}$ nor in the patient described as a neglect dysgraphic. ${ }^{4}$ Furthermore, in most reports of patients with unilateral visual neglect it is implicit that single word reading was not impaired. ${ }^{13-15}$ These observations suggest that visual neglect is not a unitary phenomenon but 


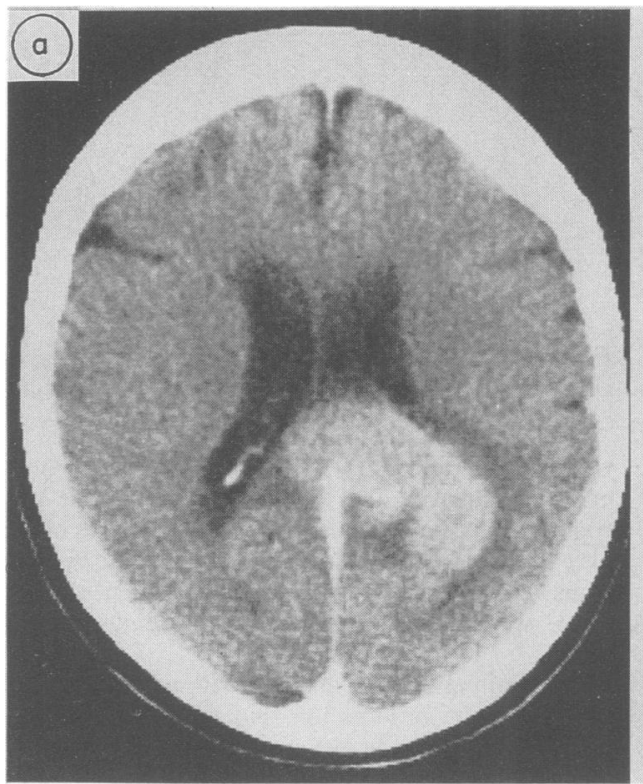

Fig 1 CT scan, 17 January 1986.

that it may be task specific which in turn makes it more plausible to suggest that there is more than a single mechanism underlying these various phenomena. The present study is of a right-handed man with a right homonymous hemianopia and a known left parieto-occipital mass extending into the right hemisphere. This patient showed evidence of a left-sided neglect dyslexia in addition to right-sided visuospatial neglect.

\section{Case report}

$\mathrm{JOH}$, a 71 year old right-handed mechanic was admitted to the National Hospital, Queen Square, on 24 January 1986 for investigation of difficulties in memory and walking which had become apparent one month previously. On examination he had a dense right homonymous hemianopia. There was mild impairment of vibration sensation in the lower limbs, otherwise motor and sensory functions were considered to be normal. Apart from the cognitive deficits to

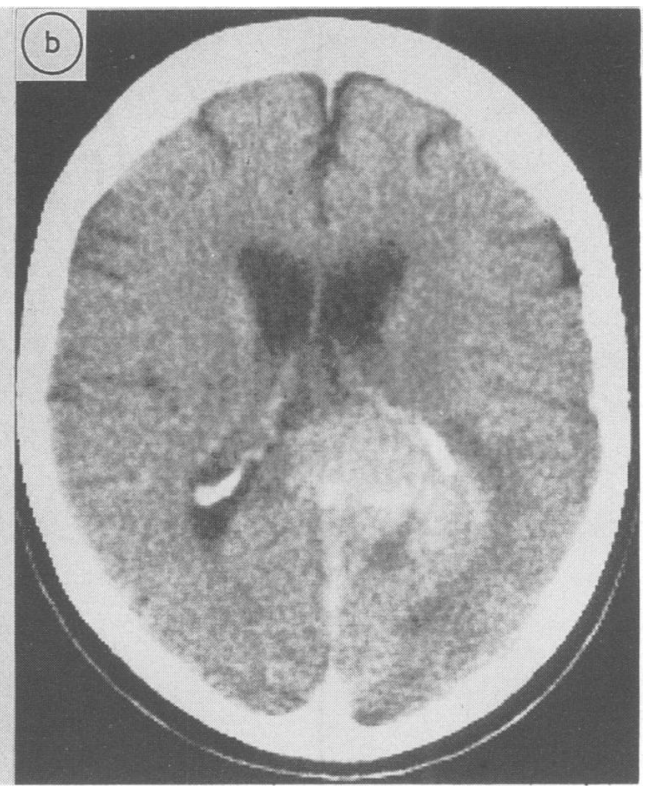

be described below there were no other neurological signs of note.

A CT scan showed a left parieto-occipital mass and four vessel angiography demonstrated this to be avascular (fig 1). A CT directed biopsy was carried out on 4 February 1986 and the histology was consistent with that of a lymphoma; a craniotomy was performed and the tumour partially removed. A further scan on 18 February 1986 demonstrated a large hyperdense mass in the left parieto-occipital region extending across the splenium of the corpus callosum into the right hemisphere. He was transferred for further therapy on 12 February 1986.

$\mathrm{JOH}$ was first referred to the psychology department on 27 January 1986 and he was tested frequently in short sessions up to the time of his discharge. He was assessed on the WAIS on 27 January 1986 and again on 11 February 1986. His test scores are given in table 1. During this period his performance on the non-verbal tests of the WAIS remained stable; there was, however, a decrement in his verbal IQ that was almost entirely due to his greater difficulty with Arithmetic and Similarities.

Clinically it appeared that his memory functions were very

Table 1 Intelligence Test Scores

WAIS

Verbal subtest scaled scores

\begin{tabular}{|c|c|c|c|c|c|}
\hline & 27 January 1986 & 11 February 1986 & & 27 January 1986 & II February 1986 \\
\hline $\begin{array}{l}\text { Arithmetic } \\
\text { Similarities } \\
\text { Digit span } \\
\text { Vocabulary } \\
\text { Verbal IQ }\end{array}$ & $\begin{array}{r}6 \\
6 \\
8 \\
10 \\
87\end{array}$ & $\begin{array}{r}4 \\
0 \\
8 \\
8 \\
74\end{array}$ & $\begin{array}{l}\text { Picture completion } \\
\text { Block design } \\
\text { Picture arrangement } \\
\text { Performance IQ }\end{array}$ & $\begin{array}{r}8 \\
7 \\
8 \\
73\end{array}$ & $\begin{array}{r}3 \\
4 \\
8 \\
77\end{array}$ \\
\hline
\end{tabular}




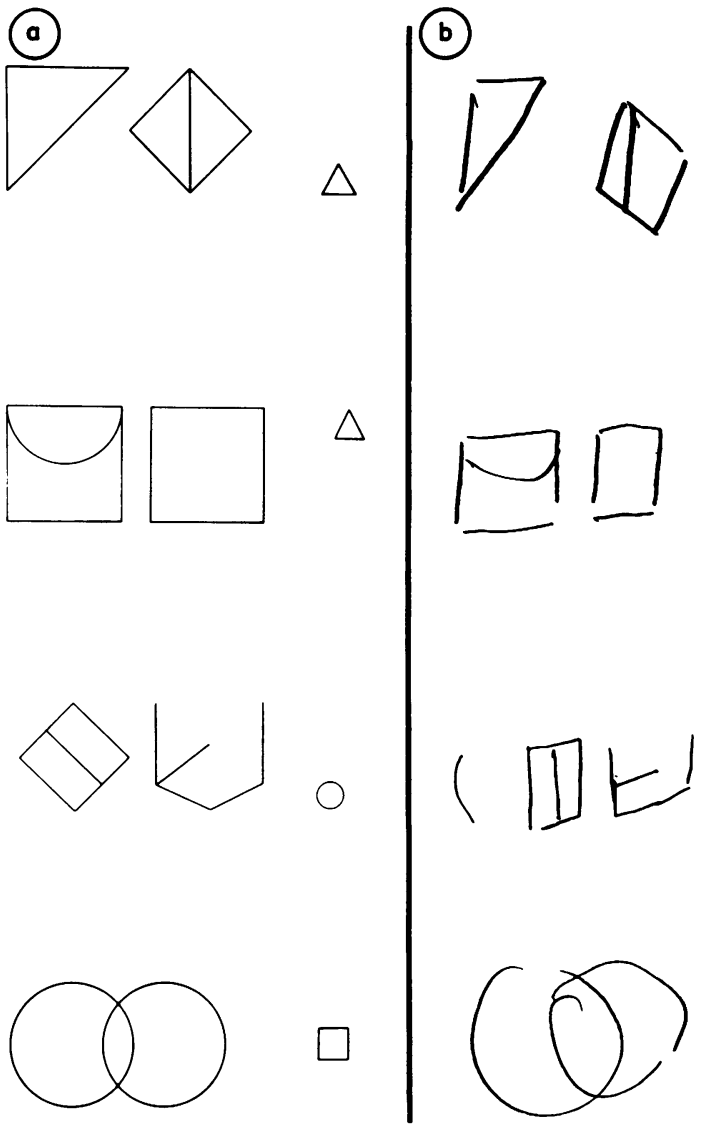

Fig 2 (a) Four designs from the Benton Visual Retention Designs test. (b) JOH's copies of each of the four patterns showing omissions of the peripheral figure on the right.

impaired in that he was insecurely orientated in time and place and his memory for recent events was poor. On a three choice recognition memory test for coloured photographs (a very easy task on which the performance of normal subjects of his age is virtually error-free) he scored only $17 / 30$.

His spontaneous speech was normal with regard to phrase length, prosody and syntax, and only occasional wordfinding difficulties were observed. On a Graded Difficulty Naming test he obtained a score of 11/30 which is at the lower half of the average range and when retested two weeks later his score had deteriorated to $3 / 20$ which is below the average range and indicative of a mild degree of nominal dysphasia. ${ }^{16}$ He scored at a dull average level on an oral and written graded difficulty spelling test (Baxter, personal communication). Although he was able to read at a similarly dull average level on the Schonell Graded Word Reading test $(55 / 100$ correct) he made numerous paralexic errors affecting the beginnings of words (for example, flower-“shower"). Other types of reading error were infrequent. He appeared to have "neglect" dyslexia affecting the left side of words.

His perceptual and spatial skills were generally weak. Thus he had considerable difficulty in identifying unusual
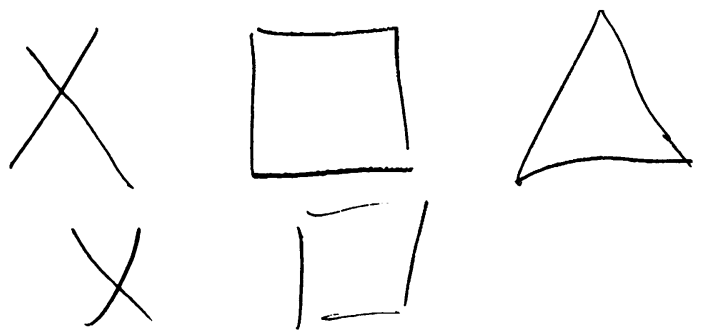

Fig 3 JOH's copy of an array of three simple geometric shapes showing the omission of the figure on the right.

view photographs of objects (4/20 correct), and he was unable to identify any Incomplete Letters. He was able to copy simple geometrical shapes but his copies of more complex shapes such as a star and a cube were spatially disorganised. It was observed that in a number of such routine visual spatial tasks administered he tended to neglect the right.

Our main interest in this case with a bilateral parietal lobe lesion was the observation that in single word reading he tended to neglect the left and that in visuo-spatial tasks he tended to neglect the right. In the following investigation we document these phenomena in more detail.

\section{Experimental investigations}

JOH was seen on several occasions between 27 January and 18 February 1986 and was presented with a selection of visuo-spatial tasks and a corpus of words to read.

\section{Visual spatial tasks}

Benton Visual Retention Designs test ${ }^{17}$ JOH was presented with Form $\mathrm{C}$ of the BVRD test. Each design was placed in front of him and he was requested to copy the design. There was no time limit. Out of a total of eight designs JOH made five errors of omission on the right-hand figures and only one omission on the left (fig 2). Subsequently JOH was asked to copy two simple designs each comprising of three main figures; he omitted to copy the figure on the right on both occasions (fig 3).

Line-Bisection task A modified version of Schenkenberg et al' $\mathrm{s}^{18}$ line bisection task was administered. This comprised of 20 black lines on a sheet of white paper $(42 \mathrm{~cm} \times 28 \mathrm{~cm})$. Eighteen of the lines were arranged in three sets of six lines so that one set lay primarily on the left side of the paper, one set lay in the centre and one lay on the right (each set contained lines of $100 \mathrm{~mm}, 120 \mathrm{~mm}, 140 \mathrm{~mm}, 160 \mathrm{~mm}, 180 \mathrm{~mm}$, and $200 \mathrm{~mm}$ ) and their position on the page randomised (fig 4). JOH was instructed to "cut each line in half by making a small pencil mark through each line as close to its centre as possible. Only to make one mark on any line and mark each of the lines without missing any". JOH tended to bisect the lines to the left of the line's actual centre (fig 4). Two of the 20 lines were excluded from the analysis because JOH's mark was some way above the line. Of the remaining 18 lines, 17 were bisected to the left of the line's actual centre, the mean deviation being $20 \mathrm{~mm}$.

\section{Single word reading}

JOH attempted to read three sets of words. Each word, 


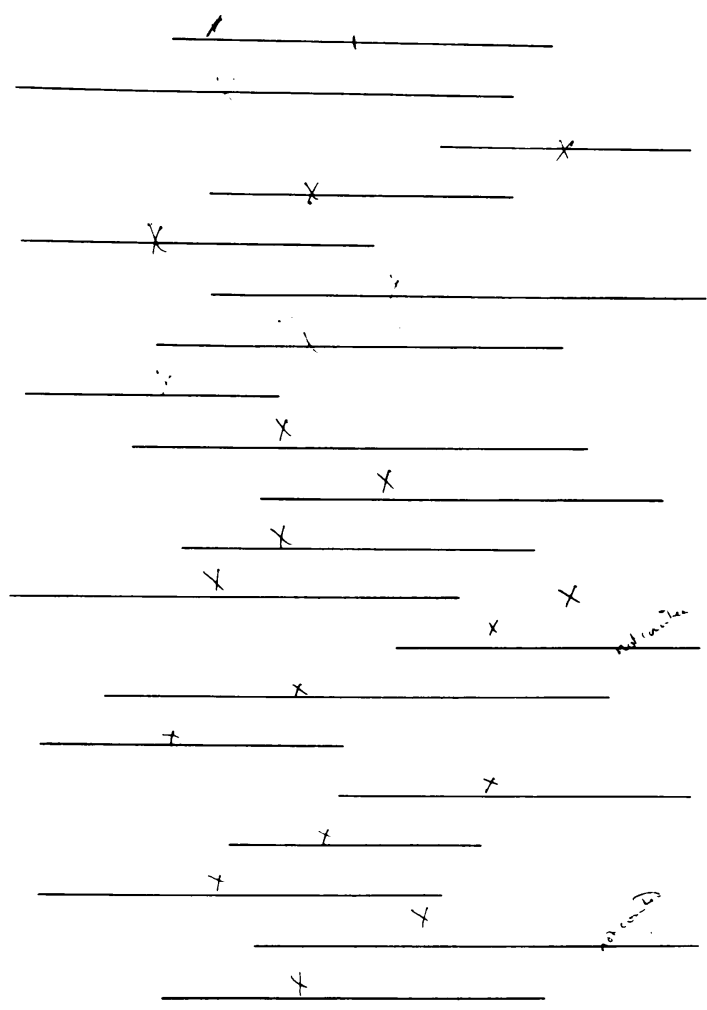

Fig 4 JOH's performance on the line bisection task showing his tendency to bisect the lines to the left of the line's actual centre.

typed in the centre of a white card $(12.8 \mathrm{~cm} \times 7.5 \mathrm{~cm})$, was presented individually. He had unlimited time to inspect and read each of the words and the order of presentation of the words within each set was randomly determined.

Set 1 High frequency words These were 348 high frequency words (A and AA frequency from the Thorndike-Lorge count). ${ }^{19}$ The percentage correct for each word length is given in table 2. Although this pool is not balanced in terms of the number of words of each letter length, there nevertheless appears to be an inverse effect of word length in so far as error rate is significantly lower for the longer words than for the shorter words $\left(\chi^{2}=18 \cdot 7, \mathrm{df}=5, \mathrm{p}<0.005\right)$.

Set 2 Compound words These were 96 compound words each of which comprised two constituent words. There were four six-letter words (for example, teapot), 35 seven-letter words (for example, bedroom), 36 eight-letter words (for example, nutshell), 15 nine-letter words (for example, farmhouse), and six 10-letter words (for example, toothbrush). $\mathrm{JOH}$ made a total of only 21 errors, 18 of which were lexical substitutions for the initial constituent word such that the whole word was a neologism (for example, eyebrowstaybrow); one error involved the second constituent word and in two neither constituent of the compound word was maintained (for example, raincoat-diplomat).

Set 3 "Split" words Subsequently JOH attempted to read words derived from splitting the two constituents of the
Table 2 Single Word Reading

\begin{tabular}{lllllll}
\hline & 2 & 3 & 4 & 5 & 6 & 7 \\
\hline $\begin{array}{l}\text { Set 1 } \\
\text { \% correct }\end{array}$ & $\begin{array}{c}67 \% \\
(12)\end{array}$ & $\begin{array}{c}66 \% \\
(145)\end{array}$ & $\begin{array}{c}53 \% \\
(79)\end{array}$ & $\begin{array}{c}71 \% \\
(41)\end{array}$ & $\begin{array}{c}86 \% \\
(22)\end{array}$ & $\begin{array}{c}86 \% \\
(49)\end{array}$ \\
$\begin{array}{l}\text { Set 3 } \\
\text { \% correct }\end{array}$ & - & $82 \%$ & $86 \%$ & $69 \%$ & - & - \\
& & $(35)$ & $(73)$ & $(35)$ & & \\
\hline
\end{tabular}

The number of words of each letter length is given in brackets.

compound word (for example, toothbrush was split into the words "tooth" and "brush" and presented separately). JOH attempted to read 143 of the "split" words. These words were of three, four, or five letters in length. The percentage correct for words of each letter length is given in table 2 . The error rate was very similar for each letter length $\left(\chi^{2}=4.933\right.$, $\mathrm{df}=2$, n.s.).

\section{Error analysis}

A total corpus of errors is given in the appendix. The following error analysis was based on his reading responses of words of three, four, and five letters from Set 1 and the high frequency words (A and AA) from Set 3. (His reading responses of two, six, and seven letters from Set 1 were excluded as the error rate was very low.) The errors were classified according to the criteria of Ellis $\mathrm{et} \mathrm{al}^{3}$ as follows: (1) Neglect errors: errors in which the target and error words are identical to the right of an identifiable neglect point in each word but in which there are no letters in common to the left of the neglect point (for example, make- - "cake", least"beast").

(2) Real Word errors: real word responses which do not meet the criteria for inclusion in the neglect category (for example, oak-“talk", value-"stable").

(3) Non-word errors: responses which were neologisms (for example, ask-“nesk"; saw-“staw").

The percentage of each type of error is given in table 3 . There does not appear to be a significant effect of word length in so far as there were comparable numbers of each type of errors for the different word lengths and for each word length there was a preponderence of neglect errors.

The 76 neglect errors have been further classified as follows:

(1) Letter substitutions: the substitution of letters to the left of the neglect point in which the word produced is the same as the target word (for example, eat-_."sat").

(2) Letter additions: the addition of letters to the left of the neglect point (for example, cap-“soap").

Table 3 Error Analysis; \% of each type

\begin{tabular}{llll}
\hline & \multicolumn{2}{l}{ Word length } & \\
\cline { 2 - 4 } & 3 & 4 & 5 \\
& $(N=53)$ & $(N=45)$ & $(N=22)$ \\
\hline Neglect errors & $60 \%$ & $60 \%$ & $77 \%$ \\
Real word substitution & $15 \%$ & $11 \%$ & $18 \%$ \\
Non-word & $25 \%$ & $29 \%$ & $5 \%$ \\
\hline
\end{tabular}


(3) Letter deletions: the deletion of initial letters of the word (for example, house-“"use").

Of the total number of neglect errors, $46 \%$ were letter substitutions, $46 \%$ were letter additions, and $8 \%$ were letter deletions. (In view of the high incidence of letter addition errors it would not be meaningful to consider these data in terms of a gradient across letter strings.)

\section{Text reading}

JOH was requested to read alound several passages from the text "The King of the Golden River" ${ }^{20}$ and passages from John Master's "Lotus and the Wind" (available in large print). His attempts were quite disorganised and he made a variety of errors of substitution, omission and addition. These errors, however, occurred both to the left and the right and the centre of the page. On no occasion did he fail to "read" to the end of a line or return to the beginning of the next line. There was thus no evidence of any unilateral spatial neglect in his reading of prose.

\section{Discussion}

$\mathrm{JOH}$, a right-handed man with a dense right homonymous hemianopia, showed evidence of a rightsided visuospatial neglect. He tended to omit figures on the right when copying designs from the Benton Visual Retention Designs test and on a line bisection task tended to bisect the lines to the left of the line's actual centre again demonstrating neglect of the right. However, when reading single words he tended to misread the beginning (that is, the left side) of the word. These findings of a right-sided visuospatial neglect and a left neglect dyslexia provide evidence of a dissociation between the two neglect phenomena.

If, as suggested by Ellis et $a l^{3}$ the reading impairment observed in neglect dyslexia occurs because a more general visual neglect compromises the reading process, $\mathrm{JOH}$ might have been expected to show evidence of either a left-sided visuospatial neglect in conjunction with his left neglect dyslexia, or evidence of right neglect dyslexia in conjunction with his right-sided visuospatial neglect. Our findings cannot therefore easily be explained in terms of a single general mechanism underlying these neglect phenomena.

The question that arises is whether these two phenomena have the same basis. That is, do they reflect the same functional deficit differing only in that they are material specific? First consider JOH's unilateral visuospatial neglect of the right. He had a dense right hemianopia and evidence of bilateral damage. We would assume his left hemisphere damage produced his right visuospatial neglect. However, on the present evidence of spatial neglect our findings would be equally attributable to faulty sensory input as to a central disorder in which there is a failure to scan the mental representation of extrapersonal space.
Secondly, turning to his neglect dyslexia which we would attribute to his right hemisphere damage, the main features were (1) there was evidence of an inverse word length effect, (2) on a word pool that might be expected to be vulnerable to neglect his performance was remarkably good and certainly better than for common shorter words, (3) in those instances when word length was not maintained additions were more frequent than deletions. A sensory input model would not predict any of these findings. First, such a model would predict word length to have an effect. The longer the word the greater the neglect resulting from a greater amount of stimulus in the "neglected" hemispatial field. But we have observed the converse effect, namely the shorter the word the higher the incidence of neglect. Secondly, one might expect compound words to be particularly susceptible to neglect type errors because if one half of the word were "neglected" the remaining letters form a complete word, but, this was not the case. Thirdly, we would argue that by definition a defect at the input stage of processing would result in either the incorrect input of or the omission of letters and that neglect errors therefore would involve either the substitution or deletion of letters. We observed a very low incidence of deletion errors and errors of addition were as frequent as errors of substitution. Each one of these effects, however, is entirely compatible with and indeed could well be predicted by a theory postulating that the neglect is a defect involving the internal representation of the printed word.

Neglect dyslexia has previously been considered as analogous to the completion phenomenon. ${ }^{21}$ Simple geometrical forms and complex meaningful figures can be reported as complete when presented across a visual field defect. ${ }^{2122}$ Furthermore, it should be noted that this effect is observed in patients with lesions of both the right and left parietal lobe. In both instances there is a faulty distribution of attention, such that visual information contralateral to the lesion appears to determine a meaningful but incorrect response.

Most accounts of the reading process assume that a word form system exists as a distinct stage in the reading process. The visual word form system is that which parses letter strings into ordered familiar units and categorises them visually. ${ }^{23}$ We suggest that the locus of the present effect would either be in the failure of transmission of information from an early stage of visual processing to a word form system or more plausibly in faulty access to that system. There appears to be an abnormal distribution of attention to the central representation such that an inappropriate wordform is activated, the visual information to the right appears to determine an incorrect real word response to the target. 
We thank Dr P Rudge for permission to investigate JOH and report our findings. We also thank Chris Brown for her help with the analysis.

\section{Appendix}

Set 1

Targe

Response

by do

it sit

my ran

of as

add ladd

age voyage

aid said

air their

art syrt

ask nesk

bed zed

bid did

big mig

but hut

can scan

cap soap

eat sat

egg mister

gay nay

get not

had fruit

he'd shed

her dyr

he's heds

how brow

how yours

I'll him

ill $\quad$ lll

it's nuts

its yts

job fob

leg beg

lip dip

low stow

man acman

net nut

not run

now how

oak talk

oil oll

old sold

our your

sad mad

saw staw

sea pea

sky whisky

son syon

sum room

tip zip

tom room

too oo

wet net
Target

$\begin{array}{ll}\text { able } & \text { stable } \\ \text { also } & \text { stalso } \\ \text { beat } & \text { beast } \\ \text { been } & \text { screen }\end{array}$

Set 3 Split-compound word

Response

book

born

cool

done

edge

else

ever

fear

fool

gave

hair

keep

kept

laid

lake

line

made

make

neck

rain

rise

roll

salt

same

skin

sing

soul

tall

this

trip

wind

wing

wish

carry

clean

dream

least

mount

ocean

party

right

story

today

valve

while

bridge

bright

charge

America

between

company

England

stook

storn

stool

alone

bedge

staelse

stover

rear

stool

dave

blair

knee

recept

zed

zake

mine

stade

cake

stick

pain

hyrse

stroll

halt

became

akin

washing

stavy

heel

tys

strip

axnd

heavy

dish

sherry

dean

scream

beast

discount

chean

forty

fright

factory

friday

stable

highhill

orange

bite

discharge

bin coin

eye ayr

net get

out cut

say sway

wam swam

back hook

cock cook

fall gadfly

nogs slides

look cook

mill will

pass nassy

wash dash

wear bear

black kick

board lard

chair hair

hedge sledge

house use

light blight

light night

shine swine

shine sunshine

white night

\section{References}

twopenny

angle forward

thought

horward

usually

rought

usual

Set 2 Compound errors

Target Response Target Response

hear year

1 Warrington EK, Zangwill OL. A study of dyslexia. J Neurol Neurosurg Psychiatry 1957;20:208-15.

2 Kinsbourne $\mathbf{M}$, Warrington EK. A variety of reading disability associated with right hemisphere lesions. J Neurol Neurosurg Psychiatry 1962;25:339-44.

3 Ellis AW, Flude BM, Young AW. Neglect Dyslexia and the Early Visual Processing of Letters in Words and Nonwords. Cognitive Neuropsychology 1987. (In press).

4 Baxter DM, Warrington EK. Neglect dyslexia. J Neurol Neurosurg Psychiatry 1983;46:1073-8.

5 Brain WR. Visual disorientation with special reference to lesions to the right cerebral hemisphere. Brain 1941;64:244-72.

6 Battersby WS, Bender MB, Pollack M, Kahn RL. Unilateral spatial agnosia (inattention). Brain 1956;79:68-93.

7 Critchley M. The Parietal Lobes. New York: Hafner, 1966.

8 Heilman KM, Velenstein E. Mechanisms underlying hemi-spatial neglect. Ann Neurol 1979;5:166-70.

9 Watson RT, Heilman KM, Cauthen JC, King FA. Neglect after cingulectomy. Neurology 1973;23:1033-7.

formica $\quad 10$ Bisiach $\mathrm{E}$, Luzzatti $\mathrm{C}$. Unilateral neglect of representational space. Cortex 1978;14:129-33.

11 Bisiach E, Luzzatti E, Perani D. Unilateral neglect, representational schema and consciousness. Brain 1979;102:609-18. 
representation of outside reality. Neuropsychologia 1981;4 543-51.

13 Paterson A, Zangwill OL. Disorders of visual space perception associated with lesions of the right cerebral hemisphere. Brain 1944;67:331-58.

14 McFie J, Piercy MF, Zangwill OL. Visual spatial agnosia associated with lesions of the right hemisphere. Brain 1950;73: $167-90$.

15 Oxbury JM, Campbell DC, Oxbury SM. Unilateral spatial neglect and impairments of spatial analysis and visual perception. Brain 1974;97:551-64.

16 McKenna P, Warrington EK. Testing for nominal dysphasia. $J$ Neurol Neurosurg Psychiatry 1980;43:781-8.

17 Benton AL. The Revised Visual Retention Test: Clinical and Experimental Applications. Iowa City: The State University of Iowa, 1963 (3rd ed).
18 Schenkenberg T, Bradford DC, Ajax ET. Line bisection and unilateral visual neglect in patients with neurologic impairment. Neurology 1980;30:509-17.

19 Thorndike EL, Lorge I. The Teachers' Word Book of 3,000 Words. New York: Columbia University, Teachers College Press, 1944.

20 Burt C. "The King of the Golden River". In: Mental and Scholastic Tests. London: Staples Press Limited, 1947.

21 Warrington EK. The effect of stimulus configuration on the incidence of the completion phenomenon. $\mathrm{Br} J$ Psychol 1965;56:447-54

22 Warrington EK. The completion of visual forms across hemianopic field defects. $J$ Neurol 1962;25:208-17.

23 Warrington EK, Shallice T. Word form dyslexia. Brain 1980;103:99-112. 